\title{
Code choice and code-switching in Swiss-German Internet Relay Chat rooms
}

\author{
Beat Siebenhaar \\ University of Berne, Switzerland
}

\begin{abstract}
In the German-speaking regions of Switzerland, dialect is spoken by all social groups in most communicative situations, Standard German being used only when prescribed. Swiss dialects rarely appeared in written form before the 1980s, apart from the genre of dialect literature. Due to the growing acceptance of informal writing styles in many European languages, dialect is increasingly employed for written personal communication, in particular in computer-mediated communication (CMC). In Swiss Internet Relay Chat (IRC) rooms, varieties of German are used side by side as all chatters have a command of both standard and dialectal varieties. Depending on the channel, the proportion of dialectal contributions can be as high as 90 percent. The choice of a particular variety depends on both individual preference and on the predominant variety used within a specific thread. In this paper I take a quantitative approach to language variation in IRC and demonstrate how such an approach can help embed qualitative research on code-switching in CMC.
\end{abstract}

KEYWORDS: Language variation, computer-mediated communication, Internet Relay Chat, German, Swiss German, dialect

\section{INTRODUCTION}

The Internet links diverse communities globally, with English as the dominant language of communication. However, especially in more interactive modes than the Web, such as chat and e-mail, the Internet also provides a forum for regional and local communication where there is normally no need for English except in the case of technical limitations due to non-Roman alphabets (cf. Paolillo 2005: 71-76): in these environments, languages other than English are commonly used. However, this phenomenon has been largely ignored in English research literature on computer-mediated communication (exceptions being Paolillo 2001; Warschauer, El Said and Zohry 2002; a special issue of Journal of Computer-Mediated Communication on the multilingual Internet, cf. Danet and Herring 2003; and a special issue of International Journal on Multicultural Societies, cf. Wright 2004). This article examines the case of German, a language with a relatively strong presence on the Internet: according to Source Global Internet 
Statistics (2003), German comes third after English and Japanese. What is more, as the Alemannic wikipedia (http://als.wikipedia.org/) demonstrates, not only Standard German but also local varieties of German can be found prominently on websites. Online communication - particularly interactive modes such as chat and e-mail - appears to promote the use of these varieties which have rarely been used previously for written communication. In this study, linguistic variation in Swiss-German Internet Relay Chat (IRC) rooms is analyzed using both quantitative and qualitative methods, thus responding to calls for a combination of the two approaches in computer-mediated communication analysis (Danet and Herring 2003).

\subsection{Standard and dialect use in German-speaking Switzerland}

Investigations into a number of Swiss-German IRC channels reveal that different varieties are used side by side. This coexistence of Standard German and different Swiss-German dialects (which have no standardized orthography) reflects the linguistic situation in German-speaking Switzerland, a situation that has already been the focus of much research (e.g. Clyne 1984; Haas 2000; Rash 1998). I will therefore only draw attention to its main points, as a backdrop to the discussion of the use of language varieties in IRC.

In the German-speaking regions of Switzerland, two varieties of German occur: Standard German and Swiss-German dialects. While the latter fulfill most communicative functions in daily life, Standard German is employed in specific domains. This is a classic example of diglossia (Ferguson 1959) in which varieties or languages are deemed functionally complementary. The main characteristic which demarcates the varieties is their usage in oral and written communication: a case of medial diglossia.

The local dialects, being the in-group variety for the Swiss, are used almost exclusively for spoken interactions between speakers of all social classes. Although the individual dialects vary considerably, there is minimal accommodation between the German-speaking Swiss. Instances when Standard German is spoken are well defined: these include plenary discussions in class, reading aloud, and discussions with people who do not understand the dialects, in which case Swiss people usually switch to Standard German. Dialect use is common even in formal situations. For instance, members of the national government are free to use their local dialect in political discussions on national TV. At the end of 2005, Swiss national TV began broadcasting weather reports in dialect rather than Standard German. Bankers can use their local dialect to advise customers regarding investments, and the same holds true for doctor-patient encounters, job interviews, and teacher-student conversations. In essence, Swiss people speak their local dialect with other Swiss-German interlocutors regardless of subject matter.

Spontaneous code-switches from dialect to Standard German are rare. Since dialects can be used almost universally, code-switches generally only occur in 
settings where the use of Standard German is required, for instance at school or in exchanges with foreigners. Code-switches from Standard German into dialect are becoming more frequent in these settings, whereas a switch back to Standard German usually has to be explicitly requested.

Even though the dialects are spoken generally, Standard German has normally remained de rigueur for written communication. Except for the dialect literature genre, which is of marginal importance, all formal texts have been written in Standard German. For example, students who converse with me in dialect always write e-mails to me in Standard German. However, in the 1980s, the conventions started to become less rigid: dialect has gradually been finding its way into channels of personal written communication such as personal letters, notes and e-mails. In contrast to Standard German, there is no standard for dialectal orthography, so personal orthographic preferences prevail, and can be inconsistent. Dialectal writing is thus subject to diversity due to a number of factors: local dialect; standard influence; individual interpretation of phoneme to grapheme rules; individual interpretation of orthographic principles (these are mainly the same as for the standard, but interpreted differently; cf. Aschwanden 2001: 61ff.; Burri 2003); regional writing traditions; and typing errors, which are especially frequent in IRC, which demands fast typing. This extensive variation does not generally impede comprehension or communication, an observation also made for Moroccan chat rooms where non-standardized Moroccan Arabic is used (Berjaoui 2001).

\subsection{Internet Relay Chat (IRC)}

Besides the Web and e-mail, another well-known Internet communication mode is the chat room. While the Web represents an asynchronous, relatively static, one-to-many form of communication, e-mail communication is an asynchronous one-to-one interaction, which for the most part corresponds to the classical letterdespite some crucial differences (cf. Georgakopoulou 2001: 1-9). In contrast, IRC enables quasi-synchronous, written, many-to-many interaction, which was not possible prior to the introduction of the Internet. In IRC, people communicate in more or less simultaneous multi-party interactions. When users join a 'channel' or 'chat room' with an IRC client program or by means of an applet in the browser, they assume a nickname, $\log$ in, and are immediately able to read messages from other users on the screen as well as write their own messages, which are presented to other users when the return key is hit. New messages are added at the bottom of a scrolling screen, which allows chatters to see new messages as they arrive. A typical IRC session arbitrarily selected from the channel \#flirt40plus is given in example $1^{1}$

Example 1: A typical IRC $\log$ from the channel \#flirt40plus with Standard German (SG) and English (E) translation 
1 mostindianer: ja schuschu_w gsehsch no herzig us so ..........gggg

SG ja schuschu_w du siehst noch hübsch aus so ....grins

E yes schuschu_w you look cute like that.... smile

2 Zigeunerin: guetä obig mitenand...

SG guten Abend miteinander

E good evening everybody

$3{ }^{* * *}$ kurtGR has joined channel \#flirt40plus

4 Lichtstrahl_w: hallo allersits

SG hallo allerseits

E hello everybody

5 *** Pinoccio-Tg has joined channel \#flirt40plus

$6 \quad * * *$ Signoff: frechling (QUIT: User exited)

$7 \quad$ *** marki has joined channel \#flirt40plus

8 schuschu_w: mostindianer gange go nachricht luege oder hesch mer do drüber ou öppis dsäge

SG mostindianer, ich gehe dieNachrichten sehen, oder hast du mir darüber auch etwas zu sagen

E mostindianer, I'm going to watch the news or can you tell me anything about that as well

9 mostindianer: salü Zigeunerin

SG hi Zigeunerin

E hi Zigeunerin

10 maik_be: hallo zigeunerin

E hello Zigeunerin

11 wELLE: hoi rote_lippen ich hab so trockene lippen

E hello rote_lippen (= red lips), I have such dry lips

12 chnebugreend: schoo weder e lozärneri, nem ech emol a, Kim-w-LU!!

SG schon wieder eine Luzernerin, nehme ich mal an, Kim-w-LU!!

E yet another woman from Lucerne, I reckon, Kim-w-LU!!

13 Ruhepol: KIm kennen wir uns?

E KIm, have we met?

$14 * * *$ Tomcat1 has joined channel \#flirt40plus

15 rote_lippe: hi maik be

E Hi maik be

16 Nickname10: hallo Zigeunerin

E hello Zigeunerin

17 Zigeunerin: salüü mostindianer

SG hallo mostindianer

E hello mostindianer 


$\begin{array}{cl}\text { mostindianer: } & \text { salü Lichtstrahl_w } \\ \text { SG } & \text { hallo Lichtstrahl_w } \\ \text { E } & \text { hello Lichtstrahl_w }\end{array}$

A normal message in IRC starts with the chatter's nickname, which the system automatically inserts in front of a message. Lines beginning with three asterisks are automatically generated system messages that report when new users join the channel, leave, or change their nicknames. These system messages (lines 3, $5-7,14)$ do not represent personal communication.

Entering an IRC channel is like entering a bar, for communication is already taking place. Example 1 starts with a message in an ongoing conversation. Mostindianer addresses schuschu_w, saying that she looks nice and annotating the message with a gggg, an emoticon which corresponds to smileys that are often used to express non-verbal aspects of communication. In line 2, Zigeunerin wishes everyone a good evening when she enters the chat room 20 seconds before the excerpt begins. In line 4Lichtstrahl_w, who entered the channel 10 seconds before, greets everyone. In line 8 schuschu_w replies indirectly to mostindianer's message in line 1. In lines 9 and 10, mostindianer and maik_be respond to Zigeunerin's greeting in line 2. In line 11, wELLE attempts to be friendly to rote lippen (red lips) by indirectly commenting on her nickname. In line 12 chnebugreend guesses Kim-w-LU's region of origin, which is quite clear as she uses LU, the official abbreviation for the canton of Lucerne, in her nickname. In line 13 Ruhepol attempts to start a conversation with Kim-w-LU. Four more greetings follow in lines 15-18.

This extract is typical of a chat session with respect to both content and the varieties used. It clearly demonstrates that Standard German and SwissGerman dialects are both used on the same channel. Lines 1, 2, 4, 8, 9, 12, 17, and 18 are written in dialect; 11 and 13 are in Standard German while 10, 15 and 16 are linguistically indeterminate messages. Despite their brevity, dialectal messages on this supraregional channel provide insights into chatters' geolinguistic backgrounds if one compares their messages to the Linguistic Atlas of German-speaking Switzerland, SDS (1962-1997). For example, Zigeunerin is from the north-eastern part of Switzerland, from the Zurich area but certainly not from the city itself: she uses the form obig 'evening' (line 2), which is abig in and around the city. Schuschu_w comes from the northern part of the canton of Bern. In line 8 she uses gange 'I go' with northern Swiss-German morphology and hesch 'you have' with a western morphology, as well as ou 'also' reproducing a western pronunciation and do 'here' reproducing a northern pronunciation. Chnebugreend in line 12 is from either the northern part of the canton of Lucerne or from southern Aargau where two typical pronunciations co-occur. On the one hand, Middle High German $i$ and $u$ have a lowered pronunciation that is reflected in the spelling as $\langle\mathrm{e}\rangle$ in weder 'again', nem 'take', lozärn 'Lucerne' and, on the other hand, o in emol 'once' reflects a pronunciation that is typical of northern Switzerland. 
With this in mind, I will first illustrate, by means of quantitative analyses, that different chat channels with the same communicative goals exemplify different standard-dialect ratios, and that this ratio can change over time. This will be followed by a brief qualitative elucidation of the reasons for these changes.

\subsection{Research on German IRC}

Early linguistic studies of IRC in both English and German discuss its intermediate status between oral and written communication modes, and the differences between computer-mediated communication and traditional written or oral communication (cf. Crystal's 2001 notion of 'netspeak', and Werry 1996). Recent German literature normally refers to the concepts of Koch and Oesterreicher (1994), who differentiate between conceptual orality and conceptual literacy. The majority of recent linguistic analyses of German IRC are qualitative studies dealing with ethnographic and interactional aspects of communication (cf. Androutsopoulos and Hinnenkamp 2001; Aschwanden 2001; Rosenau 2001; Stein 2005). Some of the latest publications do not view IRC as conversation but rather as discourse (Bittner 2003; Dürscheid 2005); as a consequence, they criticize conversation analysis as an appropriate method for researching IRC, and call for a discourse-analytic approach. In addition, research has been done on IRC as regards: in-group language (Androutsopoulos 2003a; Rellstab 2006); the expression of non-verbal aspects of communication through excessive use of graphic markers and emoticons (Beißwenger 2000; Hentschel 1998); and the grammar of inflexives ${ }^{2}$ (Hentschel 1998; Schlobinski 2001), which have their origin in CMC or are not yet frequently used outside chat rooms. IRC data are also used for grammatical analyses (Siebenhaar 2005b; Vogel 2003). Furthermore, qualitative approaches to linguistic variation have emerged within the last few years (Androutsopoulos 2003a; Androutsopoulos and Ziegler 2004; Aschwanden 2001; Christen, Tophinke and Ziegler 2005; Kelle 2000). A quantitative approach to language variation in IRC is taken by Siebenhaar (2003, 2005a, 2005b).

This brief review suggests, on the one hand, that research on Germanlanguage IRC reflects the interests of English literature (cf. Georgakopoulou 2001); on the other hand, it complements interactional and ethnographic foci with grammatical and variationist approaches, which are found less in English literature. It is striking that most of the current research employs a qualitativeinteractional method while quantitative approches such as Paolillo's (2001) social network study on variation in IRC are astonishingly rare, although IRC data are relatively easy to record, as Herring (1996: 5) already ascertained.

\subsection{Research questions}

This article wishes to draw attention to a synchronous form of CMC in a nonEnglish online community, one of the goals formulated by Danet and Herring 
(2003) in the introduction to their special issue on The Multilingual Internet of the Journal of Computer-Mediated Communication. In the context of the linguistic situation in German-speaking Switzerland, I will address the following research questions:

- What is the distribution of both Standard German and dialects within SwissGerman IRC channels?

- Does the share of these codes differ from channel to channel, or is there a general consensus on their use?

- What are the reasons for individuals' code choices?

- Since individuals code-switch when two codes are available in face-to-face communication, what are the communicative reasons for code-switching in Swiss-German IRC?

The remainder of this paper is structured as follows. Section 2 defines the relevant code-switching terminology. Section 3 presents the methodological issues in detecting varieties in chat rooms. Section 4 gives an overview of the corpus. Section 5 highlights language use on the different channels while Section 6 focuses on language choices by individual chatters. Section 7 investigates the changes in the dialect-standard ratio, and Section 8 on code-switches exemplifies the intersection of the individual and channelcentered perspectives. In conclusion, I will discuss the benefits of combining qualitative and quantitative approaches in the sociolinguistic study of IRC in Section 9.

\section{CODES, CODE ALTERNATION, AND CODE-SWITCHING}

The two varieties or codes discussed in this paper are Standard German and Swiss-German dialects. In the remainder of this article, the latter is termed simply 'dialect'. However, it must be emphasized that this encompasses a range of variability in Swiss-German dialects, as discussed above. Our cover term is justified on the basis of the similar social value and function of all SwissGerman dialects in spite of their linguistic differences. Standard German, on the other hand, is the standard language which is used in Germany and Austria as well. Code choice is determined by the medium of communication: dialects are used in oral communication while Standard German is used for written communication. However, this separation is not clear-cut since speakers have a command of both codes, and are therefore capable of switching between codes.

Code-switching has been extensively discussed in sociolinguistic literature albeit employing various terminologies. I use Auer's (1998) approach, which interprets code-switching as part of verbal action. Since chatting comprises numerous features of oral communication, code-switching terminology can be applied to the study of IRC (cf. Androutsopoulos and Hinnenkamp 2001; Warschauer, El Said and Zohry 2002). The term code-switching will be used to 
refer to communicatively and socially meaningful code alternation. This does not mean, however, that code-switches in IRC retain the same function as in face-to-face interaction. Since code-switching in IRC is both noticeable and interpretable among chatters it can be seen as communicatively and socially meaningful code alternation in IRC and in face-to-face communication alike. And while interpretations of codes and code-switching are not generally given, their interpretations are permanently performed by participants of an interaction in order to define the common context of the communicative situation. The qualitative analysis tries to uncover the participants' interpretations of the situation to explain code-switches. Code-switches can occur intersententially or intrasententially. Code-switches that cannot be assigned an interactional meaning are termed code alternation. Code alternations that occur within syntactic structures and without an interactional meaning are defined as code mixing (cf. Berruto 1997).

\section{DETECTING VARIETIES IN IRC}

As this paper aims at detecting dialect-standard variation in IRC, methodological decisions in terms of defining a variety are crucial. There are many ways of revealing the dialectal share of an IRC $\log$ file. Qualitative analysis allows a detailed view on different levels and can pinpoint various aspects of language choice. In contrast, in a quantitative approach a general decision has to be made concerning the level on which to determine what variety is actually being used. This can be either on the word, phrase, or turn level. As the detection of phrases requires a parser, which does not yet exist for Swiss German, the phrase level is not applicable for the determination of the variety in a large corpus. Furthermore, there can be mixed turns that include languages such as English, Italian, French or Turkish, which impedes an unambiguous linguistic classification of the turns. As a result, the identification of a variety has been made on the word level. However, this identification is, on the one hand, too timeconsuming to be undertaken for every word in a large corpus such as the one used here, and on the other, not every single word can be assigned unambiguously to a variety due to the fact that Standard German and dialect words are sometimes identical. A list containing 70 Standard German words that have a straightforward correspondence in the dialect was therefore compiled to be used as a comparison basis for a computer program which will go through the entire corpus. This list consists of auxiliaries, highly frequent verbs, indefinite pronouns, some adjectives, prepositions and a few nouns. ${ }^{3}$ For all standard word forms, all respective dialectal variants as well as some of the most frequent misspellings were considered.

Deciding whether a string of characters is a dialectal or a Standard German word is not a simple undertaking, for several reasons. First, there is not always a difference between dialect and Standard German words. For example, the form of the first singular present of 'to be' is bin in both Standard German and some 
dialects; its assignment to a variety is therefore ambiguous and cannot be used in the present analysis. Second, a single Standard German form often corresponds to different dialect forms. While Standard German has a strict orthography, this is not the case for the dialects. Therefore, the same pronunciation can be written in different ways, moreover in many instances, pronunciation may differ considerably. For instance, while there is only one spelling for Standard German ihr habt 'you have' ( 2 pl.), there are two morphologic forms in the dialects (hend, heit - /hend, heIt/) with different pronunciations of the vowel, including the nasal and the final plosive. Moreover, the personal pronoun can be a clitic and is therefore written in a single word together with the verb. Thus, for this single standard form there are already 30 dialectal forms in the corpus subset recorded in 2002 (cf. Siebenhaar 2005b). In spite of this diversity, however, there is no dialectal form habt corresponding to the standard spelling, which allows for a clear assignment and this word form to be used. Third, a standard character string can correspond to a non-related dialectal form. Standard German has diphthongized the Middle High German long high vowels that are preserved in all Swiss-German dialects, and accordingly, dialectal /u rs/ 'out' matches Standard German /azxs/, with the corresponding spellings uus, us, uss and aus, respectively. Nevertheless, this highly frequent preposition could not be used because in western SwissGerman dialects, including the Bernese dialect, /l/ is vocalized to [₹] before consonants. Thus, aus may not only represent Standard German 'out', but also a western Swiss-German form of als ('then', 'but', 'as'), making it an unsuitable feature for identifying a variety.

To analyze the entire corpus on the basis of this list of Standard German-dialect correspondences, an application was programmed which assigns every word of the communicative messages to either Standard German or to the dialect if this is possible on the basis of the list. A dialect - standard ratio is then calculated for the single group, for the individual chatters and for different temporal and spatial domains. As a result, it was possible to analyze more than 10 percent of all words used in the corpus.

\section{THE CORPUS}

The corpus consists of chat log files recorded from 2002 to 2005. The logged channels are run by bluewin.ch, which runs a Swiss IRC network with several regional channels. The channels are accessible via a specific IRC application or via a Java applet in any browser. Each year, the respective channels were recorded for 200 to 400 hours within one month. Essentially, two different kinds of channels were recorded:

a) regional channels named after a town or an area, with most chatters aged between 15 and 25, and coming from the respective region ${ }^{4}$ (cf. Table 1); and

b) supraregional channels named after a special interest or age group (cf. Table 2). 
Table 1: Basic information on the regional channels

\begin{tabular}{lcccccc}
\hline & \#bern & \#basel & \#zuerich & \#aargau & \#wallis & \#graubuenden \\
\hline Regional & Western & Northern & Eastern & Central & Western & Eastern \\
characteristics & urban & urban & urban & rural & alpine & alpine \\
No. of messages & 245,962 & 104,860 & 265,590 & 137,622 & 96,803 & 177,195 \\
No. of words & $1,012,512$ & 446,443 & $1,117,059$ & 560,610 & 333,741 & 626,383 \\
\hline
\end{tabular}

Table 2: Basic information on the supraregional channels

\begin{tabular}{lccccccc}
\hline & teentalk & hiphop & flirt20plus & flirt30plus & flirt40plus & flirt50plus & flirt60plus \\
\hline $\begin{array}{l}\text { Age group } \\
\text { addressed }\end{array}$ & $10-16$ & $14-24$ & $20-35$ & $30-45$ & $40-55$ & $50-65$ & $60+$ \\
$\begin{array}{l}\text { No. of } \\
\text { messages }\end{array}$ & 355,805 & 14,551 & 184,077 & 437,614 & 897,471 & 386,105 & 135,452 \\
$\begin{array}{l}\text { No. of } \\
\text { words }\end{array}$ & $1,522,009$ & 54,757 & 842,249 & $2,192,323$ & $4,648,422$ & $1,820,765$ & 686,828 \\
\hline
\end{tabular}

Consequently, these channels have users of a specific age group, or the users have a special interest in the channel, which may again be related to age. All of these channels are typical flirt-channels without specific topics. Even in the channel called \#hiphop, there is no specific coverage of music-related topics; it is rather a chat room that includes a typical hip-hop culture of interaction as described in other publications on hip-hop communication (Androutsopoulos 2003b; Rellstab 2006).

The regional channels \#bern, \#basel, and \#zuerich cover the western, northern, and eastern urban centers in the Swiss-German midlands around the respective cities. \#aargau covers a more rural area between these centers whereas \#wallis and \#graubuenden refer to the western and eastern alpine regions. The supraregional channels \#teentalk, \#flirt20plus, \#flirt30plus, \#flirt40plus, \#flirt50plus, and \#flirt60plus address a specific age group, while \#hiphop appeals to a specific age-related cultural interest. Overall, the corpus consists of 3.44 million turns including 15.86 million words.

Chatters can choose their nicknames, change their nicknames during a session, and even join a channel using other nicknames. As a result, chatters can have several online identities at any given time. Chatters may remain anonymous with respect to their real lives, while their online identities can become extremely well developed. For sociolinguistic studies, this provides an additional difficulty, as a 54-year-old male from Boston can join the channels \#zuerich and \#teentalk with an online identity of a 14-year-old girl from Zurich, or someone from Berne can visit the channel \#zuerich with their respective Bernese identity. Nevertheless, the regional and age specifications of the channels together with chatters' decisions to communicate in these channels constitute a stable basis for a fruitful undertaking in linguistic research. 
Table 3: Percentage of dialect in the different regional channels by year

\#bern \#basel \#zuerich \#aargau \#wallis \#graubuenden

\begin{tabular}{lcccccc}
\hline Dialectal share 2002 & 91 &. & 79 &. & 85 & 90 \\
Dialectal share 2003 & 93 &. & 86 & 77 &. &. \\
Dialectal share 2004 & 93 &. & 90 & 83 & 85 & 91 \\
Dialectal share 2005 & 92 & 90 & 92 & 89 & 93 & 91 \\
\hline
\end{tabular}

Table 4: Percentage of dialect in the different supraregional channels by year teentalk hiphop flirt20plus flirt30plus flirt40plus flirt50plus flirt60plus

\begin{tabular}{|c|c|c|c|c|c|c|c|}
\hline $\begin{array}{l}\text { Dialectal share } \\
2003\end{array}$ & . & . & & . & 55 & . & . \\
\hline $\begin{array}{l}\text { Dialectal share } \\
2004\end{array}$ & . & 87 & 77 & 62 & 59 & 67 & 86 \\
\hline $\begin{array}{l}\text { Dialectal share } \\
2005\end{array}$ & 93 & 88 & 71 & 63 & 56 & 65 & 79 \\
\hline
\end{tabular}

\section{DIALECT-STANDARD RATIO WITHIN DIFFERENT CHANNELS}

Following the guidelines described in Section 3, the log files of the different channels were analyzed for the dialect-standard ratio for each year. Table 3 gives the dialectal shares for the regional, Table 4 for the supraregional channels. The findings suggest that dialect and Standard German are used side by side on all channels. However, the dialectal proportion differs from channel to channel. In general, the dialectal share is higher within the regional channels than on the supraregional channels. The following sections discuss these findings in detail.

\subsection{The regional channels}

The regional channels in Table 3 reveal a generally high proportion of dialectal contributions. A comparison of the channels over the years establishes that the proportion for \#bern and \#graubuenden has been stable; it has increased slightly in \#wallis and more dramatically in \#zuerich and \#aargau, leveling out the former differences in 2005. As a result, an interesting question arises of how to explain the earlier divergence. Berne has traditionally had strong dialectal awareness, including in literature, and a wide acceptance of dialect use in current pop music, which sets it apart from the other midland cantons of Zurich and Aargau. Moreover, Zurich and Aargau are cantons that border on Germany, which may also attract German chatters, who do not have to abandon Standard German. However, Aschwanden (2001: 61) reports that German chatters have learned to write a Swiss-German dialect in order to maintain a low profile in active Swiss channels. The general rise of the dialectal share substantiates the strong position of the dialect in its written form for personal communication. As 
the dialectal share levels out at 90 percent in all regional channels, this current ceiling value may be limited by interferences from, and citations of, Standard German as well as by standard orthography.

\subsection{The supraregional channels}

The supraregional channels in Table 4 show a different picture. Their dialectal share is remarkably lower than that of the regional channels, except for very young chatters. As for most of the regional channels, the dialectal share has remained quite stable over the years. Since the different channels are defined by the age groups of their users, it is convenient to test the apparent-time hypothesis, according to which older people use an older and more traditional variety than do younger people (Labov 2001). In Switzerland the traditional variety for written communication is considered to be Standard German. The data, however, do not support this hypothesis: comparing the age groups, we find a standarddialect ratio in the form of a U. This form is regarded as typical of stable variation (Labov 2001: $101 \mathrm{ff}$.) and related to overt prestige of a variety: the middle-aged group uses the variety with the higher overt prestige while the younger and the older generations use the non-prestigious forms, corresponding precisely to the distribution found here. The middle-aged group uses more Standard German, the variety associated with overt prestige for writing, while younger and older chatters use more dialect. Thus, with reference to the apparent-time hypothesis, the distribution here does not point to a language change, but to a variation that remains stable over time. Still, this result is surprising since dialect writing in private communication only emerged in the early 1980s. The results suggest that the change in language use came about rapidly, with quite a stable situation being reached after 20 years.

\section{DIALECT-STANDARD RATIO OF INDIVIDUALS}

After considering the distribution of the varieties in the channels, I will now focus on the dialect-standard ratio of individuals. Can a distinction be made between standard chatters and dialect chatters, or do chatters use both codes? Figure 1 shows the dialect-standard ratios of all chatters with more than 100 messages in \#flirt40plus, the supraregional channel with the lowest share of dialectal variants, and in \#bern, an average regional channel. In \#flirt40plus 1156 out of 24,307 chatters contribute more than 100 messages. The figure reveals that most of these regular chatters use both varieties, albeit with a different quantitative distribution, and that 20 percent of the chatters use only Standard German, while 15 percent use only dialect. In the channel \#bern, however, 319 out of 13,146 chatters contribute more than 100 messages. Here it is obvious that most chatters (73 percent) use only the dialect, and only a few use more than just a few Standard German words. Comparing the two distributions, it becomes evident that different distributions exist both on the channel level and on the 


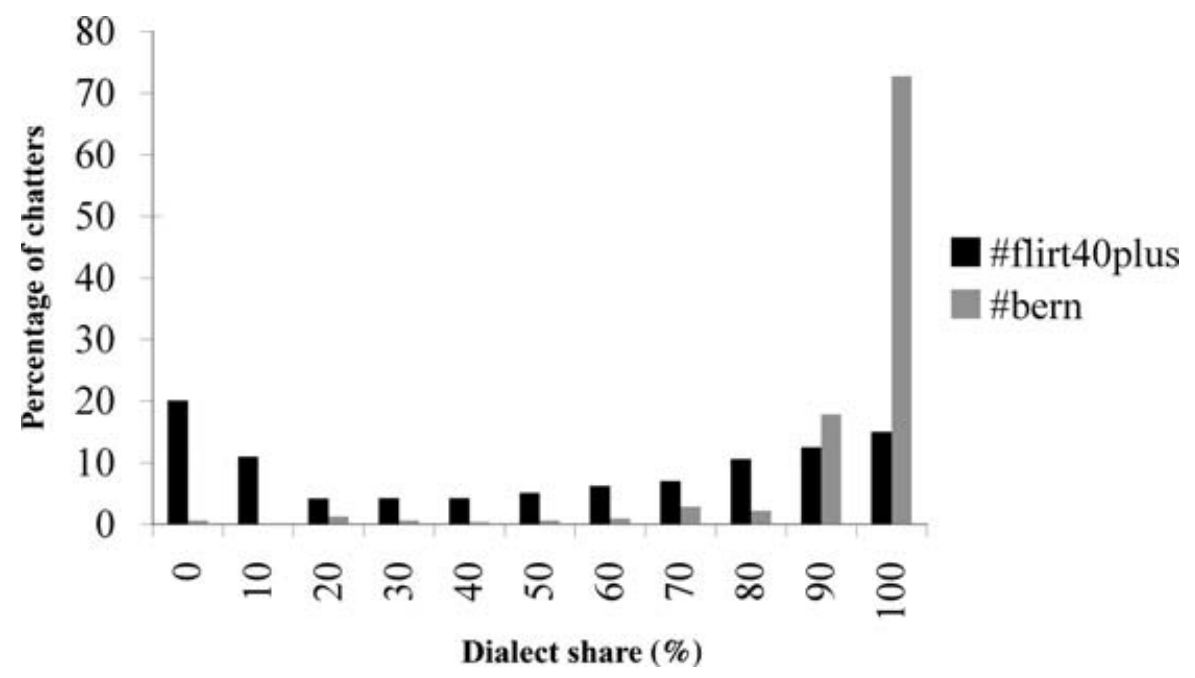

Figure 1: Dialect percent of chatters with more than 100 messages. Column 0 percent means 20 percent of chatters with more than 100 messages in channel \#flirt40plus (0.6 percent in channel \#bern) who do not use any dialectal forms

level of individual chatters: in \#flirt40plus most chatters use both codes, with a substantial minority using mainly Standard German. In the regional channel, however, most chatters use strictly dialect. While in \#flirt40plus most chatters use both varieties, in the regional channel \#bern, the formal variety learned at school, that is Standard German, is hardly ever used.

\section{CHANGES IN THE DIALECT-STANDARD RATIO}

Sections 5 and 6 have shown that variation on the channel level is reflected on the individual level in different ways. In this section I will demonstrate that, as would be expected, the dialect-standard ratio of these two channels is not constant, but changes over time. Moreover, the location of changes points to areas which are interesting for code alternation analysis. This time-dependent level of the dialect-standard ratio can be seen as an intermediate level between the global basic data of the channel given in Tables 3 and 4 and the micro level of individual interactions.

Figure 2 illustrates the development of the dialect-standard ratio in \#flirt40plus and \#bern during one hour, between 8 p.m. and 9 p.m. While the dialect share varies between 12 percent and 82 percent in \#flirt40plus, it is at 100 percent in \#bern for most of the time and only drops to values below 80 percent three times. Applying the matrix language concept of Myers-Scotton (2001) to larger interaction sequences, the matrix language can be understood 


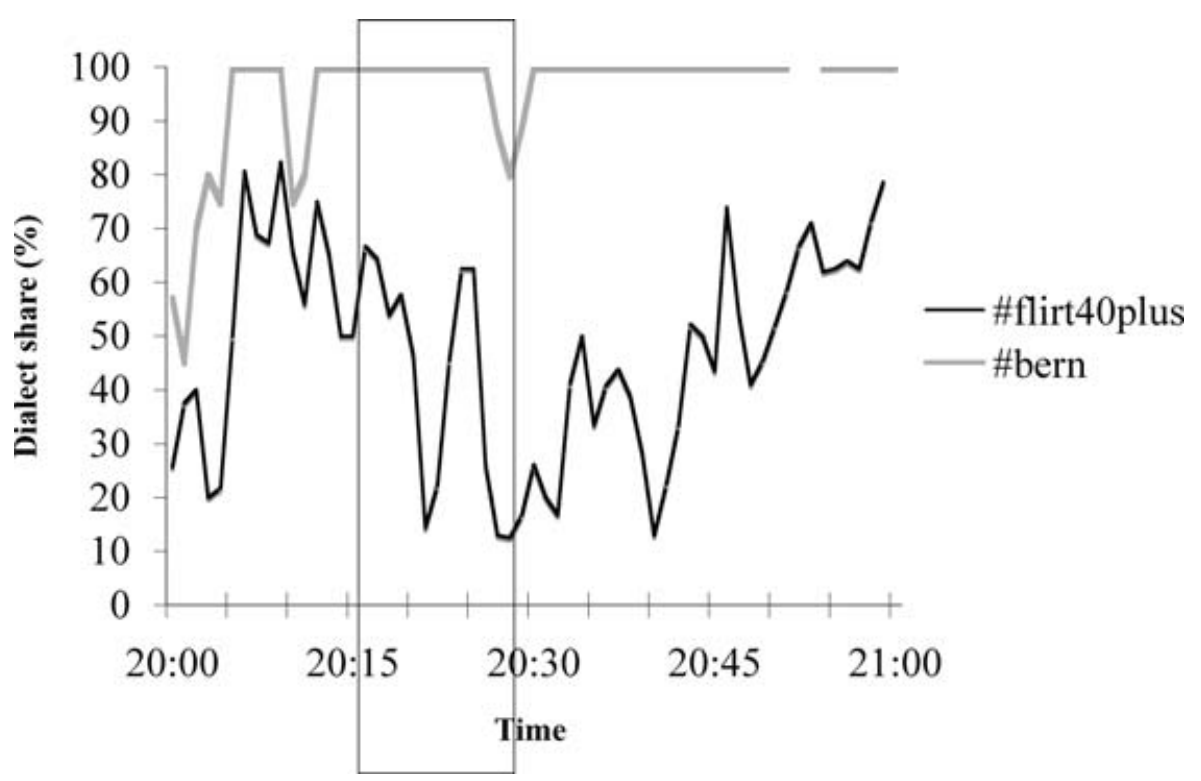

Figure 2: Development of the dialect share in \#flirt40plus (1337 turns) and \#bern (413 turns) during a recorded hour on 04/05/2005. The values represent the dialectal share in percent of the two preceding minutes at every minute. The rectangle marks the excerpt discussed in Section 7.1

as the language that predominates at specific moments (cf. Siebenhaar 2005a). The matrix language in \#bern is undoubtedly the dialect, in which a few Standard German forms are embedded. In \#flirt40plus, however, it is not clear which variety should be considered the matrix language due to the frequent changes during the time-span under investigation.

\subsection{The supraregional channel \#flirt40plus}

Let us first examine the changing values of \#flirt40plus. This one-hour passage contains 1337 lines (6567 words). Following the procedure outlined in Section 3,780 of these words were automatically attributed to either standard or dialect. As 49 percent were dialect words, the standard-dialect ratio is almost balanced and slightly below the overall mean of that channel.

The question now arising is whether any correlation with other quantitative data exists. The amount of traffic within this channel does not seem to influence chatters' language choices: testing the relation between dialectal share and the number of messages written at the same time in this passage yields an almost negligible positive correlation $(\mathrm{r}=0.05)$ that reflects the correlation in the whole data set $(\mathrm{r}=0.06)$. There is, however, a connection with the time of day as 
the dialect ratio drops significantly below the mean from 11 p.m. to 6 a.m. The higher rate of Standard German contributions in the night is due to the presence of more occasional visitors making only a few contributions: these visitors are less familiar with this particular chat room's etiquette, which corresponds to Paolillo's (2001) findings that peripheral participants are more likely to use majority languages. The main reasons for changes in the dialect-standard ratio can, therefore, presumably be found in communicative and interactional aspects rather than in quantitative correlations.

A quantitative approach nevertheless reveals its strength as it points to the positions where the dialect-standard ratio changes. It is to be expected that it is here that code-switching occurs more frequently and where motivations for a different language choice can be detected. To exemplify this I will take a closer look at the 11-minute period from 20:17 to 20:28 (cf. Figure 2). After a phase of roughly 15 minutes prior to the analyzed part with a dialect ratio of 50 percent to 80 percent, the ratio drops to 14 percent within two minutes, and rises again to 62 percent three minutes later. After remaining there for three minutes, it then drops again to 12 percent. In these 11 minutes, 45 chatters wrote 271 lines, and 36 percent of the 1141 words are attributed to dialect. 12 chatters generate two-thirds of the traffic, while five chatters use both varieties. I will return to these points in Section 8, after a closer look at the different parallel discourses.

From 20:17 to 20:20 there are different independent conversational threads taking place. A section is reproduced in Example 2. One thread is mixed, while all the others use either standard or dialect only:

Example 2: Parallel use of Standard German (SG) and dialect (D) (\#flirt40plus 04/05/2005, 20:17 to 20:18). 83 messages that do not belong to these threads have been left out (note that nicknames are truncated by the system to 10 characters)

1 Donna_44_S: cello,bisch musikalisch?

D Cello, do you have a musical talent?

2 pseudoweib: hoi Aurelia_61

D Hello Aurelia

3 Cello_m: ja es bitzli lach und du

D Yes, a little bit, smile, and you

4 silbermond: genau...ich sehe...du siehst werbung

5 SG Sure...I see... you watch commercials

5 Aurelia_61: hallo pseudoweib

Hello pseudoweib

6 Gladiator: nein. ...ich sehe buchstaben

SG No, I look at letters

7 Donna_44_S: geniali flötischtin,smile

D A brilliant flute-player, smile

8 pseudoweib: ich auch nicht lach

SG Neither do I, smile 


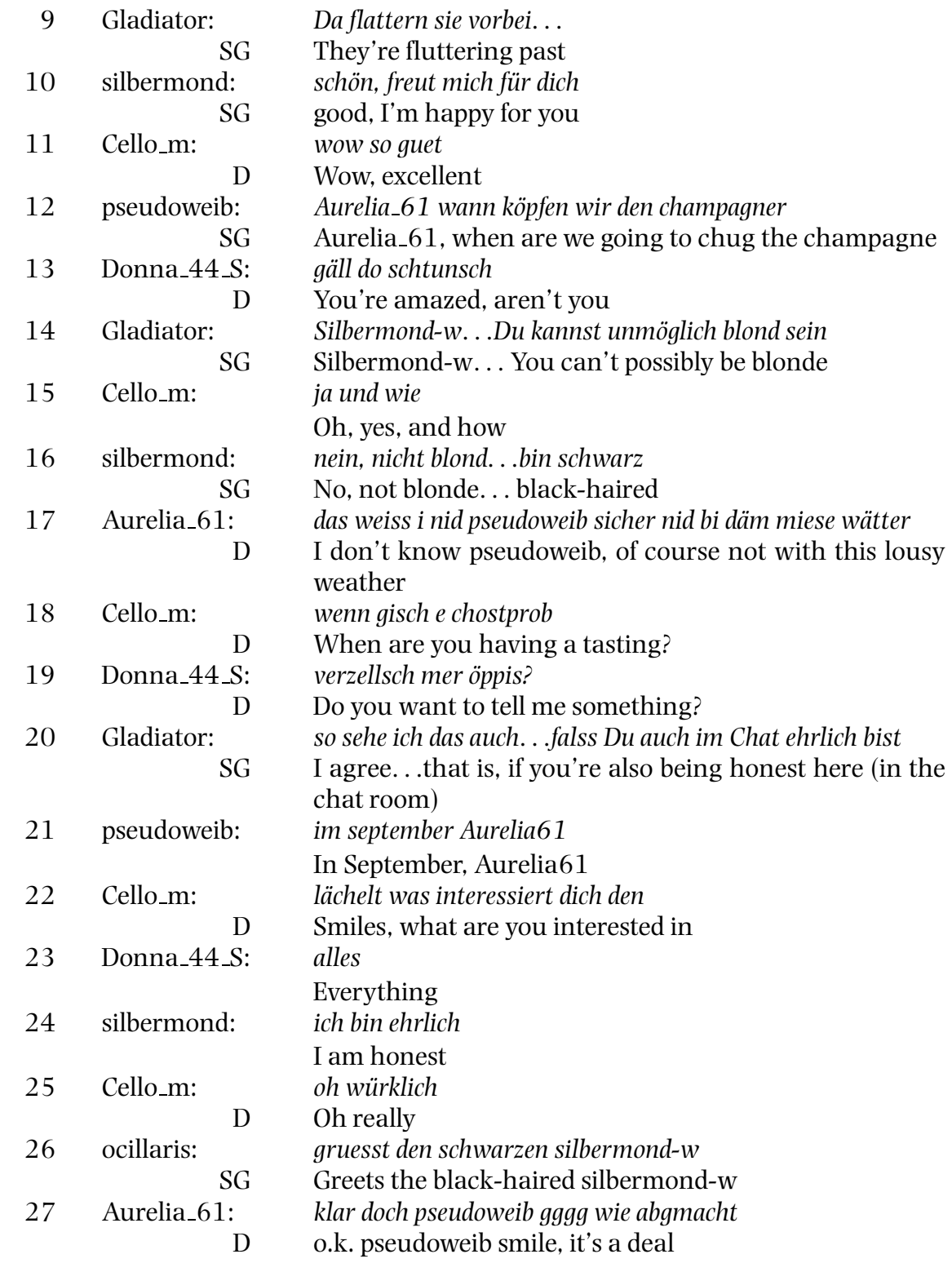

Donna_44_S and Cello_m are engaged in a discussion, both using the dialect, whereas silbermond-w and Gladiator are engaged in another discussion, both using Standard German. ocillaris, who enters this thread in line 26, also uses Standard German. silbermond-w uses both varieties throughout the corpus, but does not change codes within a single thread. It appears, then, that chatters tend 
to create cross-turn coherence by means of language choice. But this separation of threads by language choice is not compulsory: in the third thread presented here, between Aurelia_61 and pseudoweib, codes are mixed: Aurelia_61 uses the dialect, while pseudoweib uses Standard German.

At 20:21/22 and from 20:26 to 20:28 there is a group of three Standard German chatters, who are very active, while from 20:23 to 20:25 there is another thread in which two dialect chatters are involved. As a result, the main factor defining the variety in the channel is the linguistic identity of the active chatters: dialect chatters account for the rise in the dialect ratio, while mostly standard chatters give rise to the standard ratio. Figure 1, however, has shown that most chatters in \#flirt40plus use both varieties. How some chatters linguistically adapt to the thread they have joined will be illustrated in Section 8 .

The question now emerges whether the groups of standard chatters and dialect chatters keep to their own kind, or whether they mix. We have seen that the two varieties are represented at a similar level, and that each discussion group mainly uses one variety. As a result, one could hypothesize that there are two clusters of chatters consisting of a closer network structure involving minimal interaction between these groups. This hypothesis cannot, however, be upheld since evidence linking interactions of standard chatters and dialect chatters has been found, as in the case of Aurelia_61 and pseudoweib above, although chatters usually accommodate to the actual thread. A chatter who primarily uses dialect, both in general as well as in this excerpt, switches to the standard when he addresses Gladiator who is engaged in a standard-based thread. This clearly demonstrates that it is the thread that defines the choice of the variety for chatters who use both codes (cf. Siebenhaar 2005a). Nevertheless, this is only a tendency; language choice in a thread does not appear to be compulsory.

\subsection{The regional channel \#bern}

Let us now turn to channel \#bern where the dialect ratio is 100 percent for most of the hour represented in Figure 2, and drops to lower values in only three instances. With 414 lines containing 1685 words, the linguistic traffic is three times lower than in \#flirt40plus. Following the guidelines described in Section 3, 206 of these words were automatically attributed to either standard or dialect, with the dialectal level reaching 95 percent.

In the selected passage, the correlation of the dialectal share to the traffic is negligible; in the whole recording, it is again scarcely positive $(\mathrm{r}=0.08)$. Similarly, traffic decreases during night hours, which results in a correlation of the time of day. This fact can again be explained due to the presence of occasional visitors who are less familiar with chat room etiquette. Further scrutiny will now be given to the messages in \#bern that cause the dialect ratio to drop below 100 percent. Within an hour we find six messages that are not entirely written in dialect, four of which occur within the first three minutes. They are all written by contingent chatters with two, two, 10 and 14 messages within the entire corpus. 
Each of these 28 messages is an impersonal request for a date similar to the one in Example 3:

Example 3: A 'typical' Standard German message in \#bern

welche frau hat heute lust mit mir etwas trinken zu gehen? bitte im p melden Which woman would like to go out for a drink with me today? Please answer in the private room.

Throughout the corpus, one of these four chatters with Standard German messages in the selected passage writes a message in dialect, while all others are standard messages. The messages referred to here are all messages in Standard German, none of which was answered. In minute 10, a frequent chatter switches the code in a chat action (code-switching in chat actions will be discussed in Section 8). In minute 27 , we finally find a message from a regular chatter who normally writes in dialect. Here she uses Standard German guten abend 'good evening' to greet everyone, which is at the time not answered, and, perhaps as a result, she exits three minutes later without leaving another message.

The interactions in \#bern clearly differ from those found in \#flirt40plus. In \#flirt40plus most chatters are engaged in a conversation. In \#bern most of the chatters present within that hour either greet all chatters in the chat room or search for contacts with questions such as will öpper chatte? 'anybody wanna chat?' For the most part, these messages are not responded to. Many chatters with this type of message appear to be occasional visitors. The chatters engaged in interactions use the dialect without exception, irrespective of their being regular chatters or occasional visitors. The Standard German messages are mainly written by chatters who are not engaged in interactions. Only one frequent chatter (kuRupT) uses Standard German in a chat action (cf. Example 5 in Section 8).

In sum, the analysis of this sixty-minute excerpt from the regional channel, supported by additional evidence from the entire data set, illustrates clear differences to the supraregional channel \#flirt40plus. While in \#flirt40plus both varieties are used and chatters of both varieties interact with each other, the situation in \#bern is quite different. In \#bern, all Standard German messages are ignored and interaction occurs only in dialect.

\section{STANDARD - DIALECT CODE-SWITCHING}

Let us now return to the five chatters who use both varieties in the extract of \#flirt40plus described in Section 7.1. How can their code-switches be explained, and how are they placed within the corpus? One of these five chatters, who uses both varieties, has already been mentioned with a code-switch at 20:27. In this discussion $\mathrm{s} / \mathrm{he}$ uses the dialect, but when addressing a chatter outside this particular thread who uses Standard German, s/he switches to Standard German, 
too. This instance of intersentential code-switch may be regarded as addressee specification (Gumperz 1982), which is the most frequent type of code-switching in the Swiss IRC data (cf. Siebenhaar 2005a).

Example 4: Code-switching in a chat action (\#flirt40plus)

Zigeunerin mal in ihrem buch weiterliest. . . schau später nochmals rein. . . vielleicht. tschüss zemä.. :-)

(Standard German:) Zigeunerin will continue to read her book. . .I'll be back later. . maybe. (Dialect:) See you later.. :-)

Another type of code-switching is found in a chat action at 20:26 (cf. Example 4). A chat action is a distinct type of message where the user types /me followed by some text. The system substitutes the user's name for /me and indents the line or marks it with a single asterisk. These chat actions differ from normal turns in that the chatter refers to him/herself in the third person. In the analyzed Swiss IRC channels, the dialect ratio in such chat actions is much lower than in normal messages. The 1156 chatters with more than 100 messages in \#flirt40plus write 27,575 chat actions (compared to 660,441 normal messages). The dialect share in these chat actions is significantly lower than that in normal messages (19 percent as compared to 64 percent). Moreover, code-switches are significantly more frequent in these chat actions. Out of 6208 messages which contain both standard and dialect words, 1460 are chat actions. Code-switches are frequent in these chat actions because they are often based on downloaded scripts containing Standard German texts, although the embedded individual texts are written in dialect. The example given here does not seem to be based on a script, as it is only found once in the entire corpus (another example of code-switching in a chat action is discussed below in Example 5). Nevertheless, this single turn contains a type of code-switching which is extremely frequent for chatters using both varieties, in that it occurs at the edge of an interaction sequence, meaning that while the main part of the interaction is in Standard German, greetings and salutations are conveyed in dialect. While this may be regarded as the usual distribution, the contrary may also occur. In the example given above, code-switching takes place in a single message, that is a chat action. More often, however, code-switching occurs at the transition from one turn to another when the interaction moves from the initial to the central part, or from the central to the closing part. This is the type of code-switching performed by kleinefreche, who produces seven messages in this 10-minute-section. She greets everyone and is greeted mainly in the dialect, such as hoi or salü, by both dialect and standard chatters. Nevertheless, she uses Standard German, which is her main language, in longer turns. Her minimal use of dialect amounts to a mere 8 percent within the entire corpus.

A different type of code alternation is found in a single message within this one-hour passage, but it is quite common in the corpus as a whole: mer gohts au 
gut Wuscheli, danke 'I am fine, too, Wuscheli, thanks'. This is written in dialect except for gut, 'well', which is in standard rather than dialectal guet. SwissGerman dialects have preserved the Middle High German ue /uə2/, which has turned into a long monophthong u / $\mathrm{u}_{\mathbf{I}} /$ in Standard German. In written Swiss dialects, the falling diphthong is usually marked as $\langle\mathrm{ue}\rangle$, but the standard spelling with $\langle\mathrm{u}\rangle$ also occurs in the data. This particular code alternation can either be understood as a typing error or as non-functional code mixing in written text. Since a monophthongization of / $\mathrm{u}_{2} /$ does not occur in spoken dialect, I interpret this example as a typing error due to the necessity for quick replies. It does not have a recognizable function in either case, and therefore would not be considered a code-switch according to Auer's terminology (Auer 1998).

In the channel \#bern, the only code alternation (Example 5) that occurs in the analyzed one-hour extract is embedded in a chat action at 20:10, in which Standard German, Swiss-German dialects and English are all used:

Example 5: Code alternation in a chat action (\#bern)

kuRupT ist 9A5way: äSse.. * $g^{*}$ ) (9S5eit: 8:09:48 pm. Pager/ off, Log/ off) kuRupT (Standard:) is (English:) away: (Swiss German:) eating. *grin*. (Standard:) since (English:) 8:09:48 pm. Pager/ off, Log/ off.

Standard German and code-switches are frequent in chat actions in the regional channels too. At 38 percent in \#bern, the dialect share in these chat actions is significantly lower than in normal messages, which have a value of 96 percent. Of the 462 messages which contain both Standard German and dialectal forms, 93 are chat actions. Example 5 is clearly based on a script. kuRupT uses this script 41 times in the data. The spelling 9A5way for Away is striking in this script, but kuRupT uses this individual 9A5-spelling in normal messages, too. Both the Standard German and the English parts of his chat actions are always the same, while the part in the middle is variable. In most cases, as in this instance, it is in dialect. The user only has to run the script, containing a given text, and a variable part as a separate insert. The chatter may therefore not even be aware of the code alternation in a script. According to this procedure, a switch is not functional and thus its status as a code-switch remains debatable (cf. Auer 1998).

To summarize, code-switches are much more frequent in \#flirt40plus, with a more balanced ratio of the two varieties than in \#bern with its clearly predominant dialect use. On the one hand, the prototypical code-switches are most likely switches in which the chatter accommodates to the code of the addressee. On the other hand, however, code-switches occur in the opening and closing moves of a chat interaction (greetings, salutations). Not very frequently, metaphorical or discourse-related (Auer 1998: 4) code-switches can be found in which chatters take different stances in commenting on their own 
or others' messages, thus helping readers interpret messages on an attitudinal level. The use of both codes is more frequent in chat actions than in normal messages, because chat actions are based on scripts, which means that they involve two independent moments of writing: the initial writing of the script and the insertion of some individual text into the script at the moment. The alternation of the varieties, therefore, has no specific communicative function and is not defined as code-switching. While some alternations may be explained as typing errors, which have an impact on the linguistic definition of the word, these are not functional, and so they are not interpreted as code-switches, either.

\section{CONCLUSIONS}

This paper presents findings on the distribution of Swiss-German dialects and Standard German in Swiss-German IRC rooms based on an automated ascertainment of dialectal Swiss-German or Standard German words in IRC log files. While the dialectal share on the regional channels is generally higher than on supraregional channels, the latter display remarkable differences that correlate with the age of the chatters: Standard German is used more frequently by chatters of the middle-aged group, while younger and older chatters use more dialect. This distribution does not indicate an ongoing language change, but a relatively stable situation, where the middle-aged group uses the prestigious form more frequently than do other age groups. This stable situation is astonishing because dialect writing emerged only in the early 1980s and so this language use must have changed very rapidly. This emergence suggests that computer-mediated communication has an impact on language change, not only on vocabulary but also on the choice of the variety used, which is independent of the use of English.

The findings also reveal differences on the individual level. While in \#flirt40plus, the channel with the highest proportion of Standard German contributions, most chatters make use of both varieties (with one-fifth using only Standard German), the chatters in \#bern, a typical regional channel, primarily use dialect (with only one-quarter ever using Standard German words). These findings suggest that young chatters hardly ever use the written form taught at school, namely, the Standard German variety, for online chatting. This raises questions about the status of other non-standard varieties in online communities, questions that have repeatedly been addressed in communities with a nonroman writing system (e.g. Koutsogiannis and Mitsikopoulou 2003; Peel 2004; Warschauer, El Said and Zohry 2002). But what about the status of non-standard varieties in languages with a roman writing system, and what about the impact of $\mathrm{CMC}$ on their status in the standard orthography?

Tracking the dialect-standard ratio over a period of time shows that on the regional channel there are few places where Standard German interrupts a purely dialectal chat, while in \#flirt40plus the standard-dialect ratio is quite 
variable. Changing values of dialect share indicate positions where it is worth pursuing qualitative analyses on code-switching. A closer look at these positions in \#flirt40plus reveals that the variety used in a particular thread is largely maintained, and different threads are separated by distinct varieties. In general, when joining a discussion chatters adopt the variety already in use, which may cause a situational code-switch. Moreover, the findings reveal that the use of different varieties does not result in separate clusters of chatters on the supraregional channel, and explain why on regional channels, where dialect is predominant, chatters using Standard German are largely ignored. This result gives evidence for the different functions that the two varieties may have. It does, however, not imply that these functions are generally given in Swiss-German society but that the different groups may tacitly negotiate their functions. While variety distribution is more or less given in spoken language (mainly dialects) and firmly given in written language (Standard German), the distribution is still fluctuating in IRC, which comprises aspects of both spoken and written communication modes. Research on the variety distribution in IRC therefore gives rise to a new definition of the diglossic situation in German-speaking Switzerland (cf. Aschwanden 2001). It may also give prominence to the discussion of dialectstandard variation in other speech communities in the light of computer-mediated communication.

The two channels also exemplify distinct types of code alternation. On the supraregional channel where both varieties are used, situational code-switches occur when chatters join another conversational thread, resulting in addressee specifying code-switches. Similarly, code-switching takes place in order to distinguish different phases of an interaction, typically greetings. Chat actions, a distinct type of message in IRC, have a higher proportion of Standard German use. There are two types of explanation for this: on the one hand, a chatter takes a third-person stance, which is supported by a code-switch; on the other hand, chat actions are often based on scripts that are partly written outside a communicative situation. The code alternation in this latter context therefore has no communicative function. Moreover, the latter type is also the code alternation found on the regional channel, which highlights the finding that Standard German is not interactionally integrated on the dialect-based regional channels. These results undoubtedly show that research on code-switching (not only in IRC) must respect both the specific local and global environments to avoid a misinterpretation of data. Analyzing code-switching in written communication is underdeveloped; further research on varieties in IRC may thereby contribute to a better understanding of this matter.

This study clearly indicates that quantitative and qualitative research on variation in IRC can complement one another when their different findings are integrated. Together, they have shown that the use of Standard German and dialect in Swiss IRC channels varies by region and age on different levels. But it is not only the standard-dialect ratio that is different, as the quantitative research has shown; the qualitative study has revealed that the functions 
of the two varieties are also quite distinct, depending on their distribution. In this way the quantitative approach can give an overall view that might remain obscure with a qualitative analysis alone while the qualitative approach can help to explain the quantitative results that seem concealed. Research on IRC data that is relatively easy to record should therefore make use of both approaches.

\section{NOTES}

1. Line numbers have been added. IP-addresses of chatters joining the channel are omitted. Standard German translations (SG) of Swiss-German dialect sections are given to demonstrate code differences. Furthermore, nicknames are translated only when they bear reference to certain connotations. The extract has a duration of 20 seconds and was recorded on 3 May 2005, between 20:00:00 and 20:00:20.

2. Inflexives are verb stems or compounds of an object and a verb stem, which are used without any inflectional ending, i.e. *würg* 'choke' or* zungeuseheb* 'poke one's tongue out'. These forms were only used in comics prior to the Internet. Nowadays, however, they are commonly used in IRC to express feelings or to comment on one's own messages. They are usually surrounded by asterisks.

3. The list consists of the following standard word forms: habe, hab, hast, hat, hatte, hattest, hätte, hättest, gehabt (have 1-3 sing. present, past, past subjunctive, past participle); bist, ist, war, warst, gewesen (be 2-3 sing. present, 1-3 past, past participle); muss, must, musst (must 1-3 sing. present); komme, komm, kommst, kommen, kommt, käme, kämest, kämen, kämt (come 1-3 sing. pl. present, 1-3 sing. pl. past subjunctive); kann, kannst, können, könnt (can 1-3 sing., 1-3 pl. present); gesagt (say past participle); willst (will 2 sing. present); geht, gehts (go 3 sing. present); machst (make 2 sing. present); weisst (know 2 sing. present); gibst, gibt, giebt, gibts, giebts (give 2-3 sing.); schreib-, (-)schrieb(-) (write 1-3 sing., pl. present, past, past participle); nicht (not); nichts (nothing); jemand (somebody, anybody); etwas (something, anything); etwa (about); gut, gute, guter, guten, gutes (good); auch (too); wirklich (really); weiter (further); auf, aufs (on); hinauf, rauf (up); zusammen (together); hinab (down); oben (at the top); heute (today); schon (already); Zeit (time); Freund (friend); and Abend (evening).

4. Often these channels are named 'city channels'. I, however, do not use this term because it refers to urban areas, and some of the analyzed channels clearly cover rural or alpine areas.

\section{REFERENCES}

Androutsopoulos, Jannis. 2003a. Online-Gemeinschaften und Sprachvariation. Soziolinguistische Perspektiven auf Sprache im Internet. Zeitschrift für Germanistische Linguistik 31: 173-197.

Androutsopoulos, Jannis. 2003b. HipHop im Web: Zur Stilanalyse jugendkultureller Websites. In Stephan Habscheid and Ulla Fix (eds.) Gruppenstile: Zur sprachlichen Inszenierung sozialer Zugehörigkeit. Tübingen, Germany: Stauffenburg. 271-292.

Androutsopoulos, Jannis and Volker Hinnenkamp. 2001. Code-Switching in der bilingualen Chat-Kommunikation: ein explorativer Blick auf \#hellas und \#turks. In 
Michael Beißwenger (ed.) Chat-Kommunikation. Stuttgart, Germany: Ibidem. 367402 .

Androutsopoulos, Jannis and Evelyn Ziegler. 2004. Exploring language variation on the Internet: Regional speech in a chat community. In Britt-Louise Gunnarsson, Lena Bergström, Gerd Eklund, Staffan Fridell, Lise H. Hansen, Angela Karstadt, Bengt Nordberg, Eva Sundgren and Mats Thelander (eds.) Language Variation in Europe. Uppsala, Sweden: Uppsala University Press. 99-111.

Aschwanden, Brigitte. 2001. 'Wär wot chätä?' Zum Sprachverhalten deutschschweizerischer Chatter. Networx 24.

www.mediensprache.net/networx/networx-24.pdf

Accessed on 15 January 2006.

Auer, Peter. 1998. Introduction: 'Bilingual Conversation' revisited. In Peter Auer (ed.) Code-switching in Conversation: Linguistic Perspectives on Bilingualism. London/New York: Routledge. 1-24.

Beißwenger, Michael. 2000. Kommunikation in virtuellen Welten: Sprache, Text und Wirklichkeit. Eine Untersuchung zur Konzeptionalität von Kommunikationsvollzügen und zur textuellen Konstruktion von Welt in synchroner Internet-Kommunikation, exemplifiziert am Beispiel eines Webchats. Stuttgart, Germany: Ibidem.

Beißwenger, Michael (ed.). 2001. Chat-Kommunikation. Stuttgart, Germany: Ibidem.

Berjaoui, Nasser. 2001. Aspects of the Moroccan Arabic orthography with preliminary insights from the Moroccan computer-mediated communication. In Michael Beißwenger (ed.) Chat-Kommunikation. Stuttgart, Germany: Ibidem. 431-465.

Berruto, Gaetano. 1997. Code-switching and code-mixing. In Martin Maiden and Margaret Mair Parry (eds.) The Dialects of Italy. London and New York: Routledge. 394-400.

Bittner, Johannes. 2003. Digitalität, Sprache, Kommunikation. Berlin: Schmidt.

Burri, Gabriela. 2003. Spontanschreibung im Chat. Linguistik online 15: 3-31. www.linguistik-online.com/15_03/burri.pdf Accessed on 15 January 2006.

Christen, Helen, Doris Tophinke and Evelyn Ziegler. 2005. Chat und regionale Identität. In Sabine Krämer-Neubert and Norbert Richard Wolf (eds.) Bayerische Dialektologie. Akten der Internationalen Dialektologischen Konferenz, 26-28 February 2002. Heidelberg, Germany: Winter. 425-438.

Clyne, Michael. 1984. Language and Society in the German-speaking Countries. Cambridge, U.K.: Cambridge University Press.

Crystal, David. 2001. Language and the Internet. Cambridge, U.K.: Cambridge University Press.

Danet, Brenda and Susan C. Herring. 2003. Introduction: The Multilingual Internet. Journal of Computer-Mediated Communication 9. http://jcmc.indiana.edu/vol9/issue1/intro.html Accessed on 25 January 2006.

Dürscheid, Christa. 2005. Medien, Kommunikationsformen, kommunikative Gattungen. Linguistik online 22: 3-16.

http://www.linguistik-online.de/22_05/duerscheid.pdf

Accessed 17 February 2006.

Ferguson, Charles. 1959. Diglossia. Word 15: 325-340.

Georgakopoulou, Alexandra. 2001. Computer-mediated communication. In Jef Verschueren, Jan-Ola Östman, Jan Blommaert and Chris Bulcaen (eds.) Handbook of Pragmatics (2001 installment). Amsterdam, The Netherlands and Philadelphia, Pennsylvania: Benjamins. 1-20.

Gumperz, John J. 1982. Discourse Strategies. Cambridge, U.K.: Cambridge University Press. 
Haas, Walter. 2000. Die deutschsprachige Schweiz. In Hans Bickel and Robert Schläpfer (eds.) Die viersprachige Schweiz. Aarau, Switzerland: Sauerländer. 57-138.

Hentschel, Elke. 1998. Communication on IRC. Linguistik online 1. http://www.linguistik-online.com/irc.htm

Accessed on 15 January 2006.

Herring, Susan C. 1996. Introduction. In Susan C. Herring (ed.) Computer-Mediated Communication. Linguistic, Social and Cross-Cultural Perspectives. Amsterdam, The Netherlands and Philadelphia, Pennsylvania: Benjamins. 1-10.

Kelle, Bernhard. 2000. Regionale Varietäten im Internet - Chats als Wegbereiter einer regionalen Schriftlichkeit? Deutsche Sprache 4: 357-371.

Koch, Peter and Wulf Oesterreicher. 1994. Schriftlichkeit und Sprache. In Hartmut Günther and Otto Ludwig (eds.) Writing and its Use. An Interdisciplinary Handbook of International Research (volume 1). Berlin and New York: De Gruyter. 587604.

Koutsogiannis, Dimitris and Bessie Mitsikopoulou. 2003. Greeklish and Greekness: Trends and discourses of 'glocalness'. Journal of Computer-Mediated Communication 9. http://jcmc.indiana.edu/vol9/issue1/kouts_mits.html

Accessed on 16 February 2006.

Labov, William. 2001. Principles of Linguistic Change. Volume 2: Social Factors. Malden, Massachusetts and Oxford, U.K.: Blackwell.

Myers-Scotton, Carol. 2001. The matrix language frame model: Development and responses. In Rodolfo Jacobson (ed.) Codeswitching Worldwide II. Berlin/New York: Mouton de Gruyter. 23-58.

Paolillo, John C. 2001. Language variation on Internet Relay Chat: A social network approach. Journal of Sociolinguistics 5: 108-213.

Paolillo, John. 2005. Language diversity on the Internet. In UNESCO Institute for Statistics (ed.) Measuring Linguistic Diversity on the Internet. Paris: UNESCO. 43-89. http://unesdoc.unesco.org/ulis/cgi-bin/ulis.pl?catno=142186 Accessed on 16 February 2006.

Peel, Richard. 2004. The Internet and language use: A case study in the United Arab Emirates. International Journal on Multicultural Societies 6: 146-158.

Rash, Felicity J. 1998. The German Language in Switzerland: Multilingualism, Diglossia and Variation. Bern, Switzerland: Lang.

Rellstab, Daniel. 2006. Rüpple statt Schwüpple - Genderplay im \#hip-hop. In Christa Dürscheid and Jürgen Spitzmüller (eds.) Perspektiven der Jugendsprachforschung/Trends and Developments in Youth Language Research. Frankfurt/Main, Germany: Peter Lang. 201-226.

Rosenau, Heinz. 2001. Die Interaktionswirklichkeit des IRC. Networx 18. http://www.mediensprache.net/networx/networx-18.pdf Accessed on 15 January 2006.

SDS = Sprachatlas der deutschen Schweiz. Begründet von Heinrich Baumgartner und Rudolf Hotzenköcherle. In Zusammenarbeit mit Konrad Lobeck Robert Schläpfer, Rudolf Trüb und unter Mitwirkung von Paul Zinsli, herausgegeben von Rudolf Hotzenköcherle. (1962-1997) Bern, Switzerland, Vol. VII and VIII. Basel, Switzerland: Francke.

Schlobinski, Peter. 2001. ${ }^{*}$ knuddel - zurueckknuddel - dich ganzdollknuddel*. Inflektive und Inflektivkonstruktionen im Deutschen. Zeitschrift für germanistische Linguistik 29: 192-218.

Siebenhaar, Beat. 2003. Sprachgeographische Aspekte der Morphologie und Verschriftung in schweizerdeutschen Chats. Linguistik online 15: 125-139. 
http://www.linguistik-online.com/15_03/siebenhaar.pdf

Accessed on 15 January 2006.

Siebenhaar, Beat. 2005a. Varietätenwahl und Code-Switching in Deutschschweizer Chatkanälen. Networx 43.

http://www.mediensprache.net/networx/networx-43.pdf

Accessed on 15 January 2006.

Siebenhaar, Beat. 2005b. Die dialektale Verankerung regionaler Chats in der deutschsprachigen Schweiz. In Eckhard Eggers, Dieter Stellmacher and Jürgen Erich Schmidt (eds.) Moderne Dialekte - Neue Dialektologie. Stuttgart, Germany: Steiner (ZDL-Beihefte 130). 691-717.

Source Global Internet Statistics. 2003. Sources and References.

http://www.global-reach.biz/globstats/refs.php3

Accessed on 15 January 2006.

Stein, Dieter. 2005. Distanz und Nähe in interaktiver Internetkommunikation. In Michael Beißwenger and Angelika Storrer (eds.) Chat-Kommunikation in Beruf, Bildung und Medien: Konzepte - Werkzeuge - Anwendungsfelder. Stuttgart, Germany: Ibidem. 339-347.

Vogel, Petra. 2003. Passiv in deutschsprachigen Chats. Eine Korpusanalyse. Linguistik online 15: 141-160. http://www.linguistik-online.de/15_03/vogel.pdf Accessed on 15 January 2006.

Warschauer, Mark, Ghada R. El Said and Ayman Zohry. 2002. Language choice online: Globalization and identity in Egypt. Journal of Computer-Mediated Communication 7. http://jcmc.indiana.edu/vol7/issue4/warschauer.html Accessed on 15 January 2006.

Werry, Christopher C. 1996. Linguistic and interactional features of Internet Relay Chat. In Susan C. Herring (ed.) Computer-Mediated Communication. Linguistic, Social and Cross-Cultural Perspectives. Amsterdam, The Netherlands and Philadelphia, Pennsylvania: John Benjamins. 47-63.

Wright, Sue (ed.). 2004. Multilingualism on the Internet. Theme Issue, International Journal on Multicultural Societies 6 (February 2004). UNESCO Social and Human Sciences.

http://www.unesco.org/shs/ijms Accessed on 15 January 2006.

Address correspondence to:

Beat Siebenhaar
Institut für Germanistik
Universität Bern
Länggassstr.49
3000 Bern 9
Switzerland
beat.siebenhaar@germ.unibe.ch

